\title{
Differing impacts of two major plant invaders on urban plant-dwelling spiders (Araneae) during flowering season
}

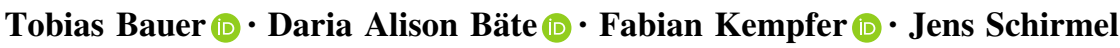

Received: 15 May 2020/Accepted: 21 December 2020/Published online: 18 January 2021

(C) The Author(s) 2021

\begin{abstract}
Plant invasions can have major impacts on ecosystems and influence global species diversity. In Central Europe, Himalayan balsam (Impatiens glandulifera) and American goldenrods (Solidago canadensis and S. gigantea) are important invaders often establishing dense and homogeneous stands, especially in urban and other disturbed habitats. We investigated their impacts on plant-dwelling spiders (abundance, family structure, guild structure) and potential spider prey items during flowering season within an urbanized landscape using a paired design comparing invaded and native reference vegetation plots. In general, flowering American goldenrods and Himalayan balsam had no significant impacts on the spider family composition. Invasion of American
\end{abstract}

Supplementary Information The online version contains supplementary material available at https://doi.org/10.1007/ s10530-020-02452-w.

T. Bauer $(\square)$

State Museum of Natural History Karlsruhe,

Erbprinzenstr. 13, 76133 Karlsruhe, Germany

e-mail: tobias.bauer@smnk.de

T. Bauer - J. Schirmel

Institute for Environmental Sciences, iES Landau,

University of Koblenz-Landau, Fortstraße 7,

76829 Landau, Germany

D. A. Bäte · F. Kempfer

Institute of Geography and Geoecology, Karlsruhe

Institute of Technology, Kaiserstraße 12,

76131 Karlsruhe, Germany goldenrods further had no effect on total spider abundance and potential prey item abundance. In contrast, goldenrods showed a significantly increased crab spider (Thomisidae) abundance while being less inhabited by web builders. Himalayan balsam negatively influenced free hunters and running crab spider (Philodromidae) abundance, while we found no effects on other groups and total spider abundance. For Himalayan balsam, potential prey item abundance was higher than in native vegetation stands. Notwithstanding that our results only represent a snapshot of the system, they suggest that large-scale removal of urban goldenrod stands during flowering season might negatively influence local spider abundance, especially of crab spiders. Management efforts should therefore be accompanied by compensation measures to avoid disruptive effects on local plant-dwelling spider communities.

Keywords Impatiens glandulifera $\cdot$ Novel ecosystems · Philodromidae - Solidago canadensis . Solidago gigantea . Thomisidae · Urban management

\section{Introduction}

Biological invasions can have tremendous ecological and socio-economic consequences (Sala et al. 2000; Nentwig et al. 2018). Invasive alien plant species are 
one of the major drivers of current global biodiversity erosion (Bellard et al. 2016; Simberloff et al. 2013), yet their eradication can result in enormous costs (Hoffmann and Broadhurst 2016; Pimentel et al. 2005).

In general, invasive plants have negative effects on animal diversity, fitness and abundance (Schirmel et al. 2016). However, the consequences and severity of invasions can vary over time and among different spatial scales, ecosystems and taxa (Dostál et al. 2013; Hulme et al. 2013; Schirmel et al. 2016). Herbivore communities are often directly affected by alien plant invasions due to loss of indigenous vegetation (Gerber et al. 2008; Procheş et al. 2008) and respond with a significant reduction of biomass and species diversity (Schirmel et al. 2016). Invasive plants can also negatively affect predator communities by altering habitat conditions (e.g., Balkenhol et al. 2018; Gerber et al. 2008) and might lower foraging success of some predators (Maerz et al. 2005).

On the other hand, there are well-known examples where invasive plants can facilitate some native species (Rodriguez 2006). Invasive plants may offer suitable resources and habitat requisites for native animals, such as web attachments for spiders (Pearson 2009), habitat analogues for small mammals (Packer et al. 2016) or pollen and nectar supplies for pollinators (Davis et al. 2018; Russo et al. 2016). Especially in landscapes with large proportions of urban and novel habitats, alien plant species are abundant (Kowarik 1995) and can contribute to local biodiversity conservation by facilitation of native animal species (Buchholz et al. 2015; Hausmann et al. 2016; Packer et al. 2016; Rodriguez 2006). Urban greenspaces, gardens, wasteland and parks might even be important habitat analogues for rare or endangered arthropod species (e.g., Buchholz et al. 2018; Eckert et al. 2017) as well as apex predators like birds of prey (Boal and Dykstra 2018).

In Europe, both Himalayan balsam (Impatiens glandulifera Royle) and American goldenrods (Solidago canadensis L., Solidago gigantea Ait.) have been actively introduced during the last few centuries as ornamental and nectar plants (Beerling and Perrins 1993; Weber 2000); nowadays, these species are very widespread and common in a wide variety of habitats in many regions of Germany (Nehring et al. 2013). Himalayan balsam is a tall, annual herb with a height of up to $2.5 \mathrm{~m}$ that flowers in late summer and reacts with fast dieback after initial frost events in autumn (Beerling and Perrins 1993). Its relatively large seeds are released by ballistochory and are able to germinate synchronously in spring. Today, the conspicuous purple or pink flowers are a typical aspect of many riparian and forest edge habitats in Central Europe. In the European Union, Himalayan balsam is considered an invasive plant species (Reg. 1143/2014; European Union 2014). However, reported effects of Himalayan balsam on local plant diversity are partly contradictory. While Hulme and Bremner (2006) showed a reduction in local plant diversity due to the replacement of widespread, but native ruderal species by Himalayan balsam, no significant effects on plant diversity were found by Hejda and Pyšek (2006) and Čuda et al. (2017). American goldenrods are rhizomatous perennial plants with a shoot height of up to $2 \mathrm{~m}$, typically invading disturbed sites where they form dense stands with rich, yellow flowers in late summer and autumn (Weber 2000). American goldenrod species are considered invasive in Central Europe (Nehring et al. 2013) due to their known negative effects on local plant diversity (Hejda et al. 2009; Weber 2000).

Impacts of both Himalayan balsam and American goldenrods on native animal diversity are still not fully understood, and past research mainly focused on their effects on pollinators and ground-dwelling arthropods. Himalayan balsam offers extensive floral resources for pollinators and can facilitate native pollinators to some extent (Davis et al. 2018; Lopezaraiza-Mikel et al. 2007). On the other hand, Tanner et al. (2013) demonstrated strong negative effects on foliagedwelling arthropod diversity and abundance. The invasion of American goldenrods can negatively affect pollinator communities in protected areas and in abandoned arable fields due to its dense stands, competitive advantage and subsequent simplification of floral resources (Fenesi et al. 2015; Morón et al. 2009). In contrast, it was shown that a relatively high number of native pollinator insects, such as wild bees (Weber 2000; Westrich 2019), visit flowering American goldenrods. However, there is a clear research gap in analyzing the impact of these major plant invaders on higher trophic levels (White et al. 2006), such as plant-dwelling predatory arthropods like spiders (Araneae). Especially during flowering season, invasion by Himalayan balsam and goldenrods may 
affect spiders via influences on phytophagous and flower-visiting insect prey items.

Crab spiders (Thomisidae) are particularly well known ambush hunters, as they lurk on flowers for visiting pollinators. Because both plant invaders produce very conspicuous flowers or inflorescences, they provide potential hunting grounds especially for crab spiders. Many spiders are habitat specialists with a fast reaction to environmental changes and stress (Hänggi et al. 1995; Buchholz et al. 2015, 2018; Entling et al. 2007). Additionally, spider diversity is usually not related to plant species numbers (Buchholz 2010; Buchholz et al. 2018; Harry et al. 2019), but rather to the structure and microclimate of the habitat (Clausen 1986). There is also evidence that spiders can react to higher prey availability with increased production of offspring (Wise 1979) and survival rates (Bradley 1993), which makes them excellent indicator species for a comparison of (indirect) local effects caused by plant invasions.

In this study, we aimed to analyze the effect of Himalayan balsam and American goldenrods on the abundance, family composition and guild structure of plant-dwelling spiders during the flowering season. We collected spiders and potential prey organisms with sweeping nets and used a paired design (for both Himalayan balsam and American goldenrods) by comparing invaded and uninvaded plots within the city of Karlsruhe in southwest Germany.

We hypothesized that flowering Himalayan balsam and American goldenrods with their rich and simultaneously developed floral presence in late summer (i) positively affect the abundance of potential spider prey organisms (insects), and (ii) affect total abundance, guild structure and family composition of plant-dwelling spiders, whereby flower-dwelling crab spiders (Thomisidae) show higher abundances in invaded plots compared to native vegetation because of a higher presence of floral resources.

\section{Material and methods}

Study area and site selection

The study was conducted within the city of Karlsruhe (Baden-Württemberg, Germany; Fig. 1a). In Karlsruhe, Himalayan balsam (Impatiens glandulifera Royle; Balsaminaceae) as well as two American goldenrod species (Solidago canadensis L., S. gigantea Ait.; Asteraceae) are widespread in numerous disturbed urban habitats such as parks, areas along artificial channels and in abandoned industrial wastelands. Major areas of Karlsruhe are located in the Upper Rhine valley on Pleistocene sand and gravel (Karlsruhe 1999). The urban vegetation in open green spaces of Karlsruhe is characterized by a mosaic of extensively managed meadows with 1-2 cuts and intensively managed lawns (from 3-5 up to 12 cuts per year). An establishment of goldenrod and Himalayan balsam on these sites is prevented by a first cut in spring (intensively managed lawns) or summer (June/ July; extensively managed meadows). Goldenrod and Himalayan balsam stands are therefore restricted to ruderalized areas with no regular management, like anthropogenic riparian habitats, irregular managed waysides, urban scrub understory or wastelands. During our collection period, patches of ruderalized herbaceous vegetation were the only type of higher and flowering herbaceous vegetation in Karlsruhe due to the cutting of the surrounding lawns and meadows.

We selected 18 American goldenrod and 20 Himalayan balsam plots as "invaded" sites (Fig. 1b, c). All of these plant stands developed spontaneously and were not planted. All plots represented dense, clearly confined and flowering stands with at least 20 single invader plant stems with a very high dominance ( $>80 \%$ cover) embedded in a mosaic of various small-scale land use unities like urban forest and scrub, meadows and impervious surface. We avoided sampling very small and highly isolated plots with a size of $<3 \mathrm{~m}^{2}$ (e.g., isolated by mowing of adjacent vegetation).

In direct vicinity to each invaded plot (about 10 to $20 \mathrm{~m}$ ) a corresponding reference plot ("native") of similar size with comparable vegetation structure (height and cover) and similar adjacent habitats was selected $\left(\mathrm{N}_{\text {total }}=76\right.$ plots; see Fig. 1$)$. The native plots are characterized by common and tall, native ruderal plant species such as Urtica dioica L., Cirsium sp., Artemisia vulgaris L., Lythrum salicaria L. and, Lapsana communis L. (see supplementary material Table 1). Native plots further contained several (dry) grasses such as Dactylis glomerata L. and other common species of Poaceae. In some native plots, single alien Erigeron annuus (L.) Pers. plants were present, but never in high numbers. Total vegetation 


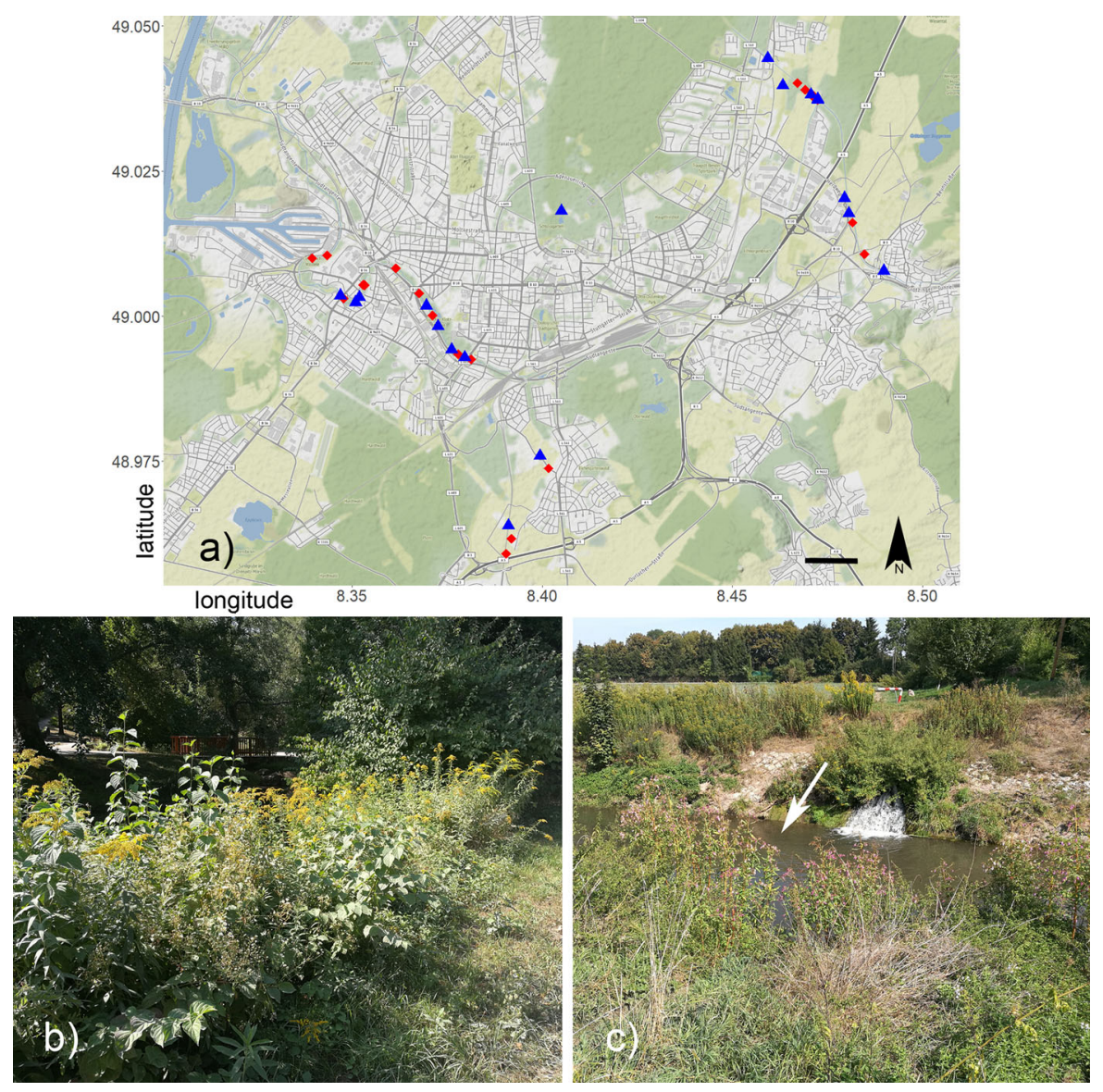

Fig. 1 Sampling localities in and around the city of Karlsruhe, Germany. a Map of all sampling plots for Himalayan balsam Impatiens glandulifera (red rhombs) and American goldenrods Solidago gigantea/canadensis (blue triangles). Native reference plots (not shown) were located in direct vicinity of the invaded

cover was over $>90 \%$ in each plot (native and invaded).

\section{Data collection}

We collected plant-dwelling spiders and potential prey organisms once per plot with a sweeping net in late August/beginning of September 2018 on clear, sunny and windless days. Per plot, twenty sweeps in the upper part of the vegetation were conducted by a single collector (FK), each sweep targeting different plants of the plot. In invaded plots, only plant individuals of the invasive species (either goldenrods or Himalayan balsam) were sampled. In order to avoid killing protected species (by German law) such as wild bees, sweeping net content was emptied onto a large plots (Map tiles by Stamen Design, under CC BY 3.0. Data by OpenStreetMap,under ODbL). b Example of an invaded site by American goldenrod. c Example of a disturbed riparian habitat invaded by Himalayan balsam (white arrow). Scale bar $=1 \mathrm{~km}$

white sheet in the field, and spiders were transferred to $80 \%$ ethanol with tweezers. To prevent spiders and prey organisms from escaping, a second person watched the margin of the white sheet for fleeing individuals. Additionally, this collection method allows for instant preservation of juvenile (and often very fragile) spiders, which are sometimes damaged beyond identification or morphospecification (e.g., loss of all legs or abdomen) when transferred together with larger and more sclerotized insects (true bugs, beetles) and plant parts directly into a killing agent and transported to the laboratory. Because most caught specimens were juveniles (as typical for this time of the year; Nentwig et al. 2019) all specimens were identified only to family level with the help of the online determination key of Nentwig et al. (2019) by 
$\mathrm{DAB}$ and FK. TB verified the identification of the specimens. Numbers of prey items were counted up to 5 individuals, and then further assessed by intervals of five (until 20 individuals) and 10 ( $>20$ individuals), since counting in the field was done on living and moving prey items of variable size and form, which prevented an exact count.

Spider nomenclature follows the World Spider Catalog (2019). To analyze the functional diversity of spider guilds, all specimens were classified into "web builders" (spiders that use a silken web to subdue and/ or sense prey; e.g., Araneidae and Theridiidae) and "free hunters" (spiders that hunt prey without a web; e.g., Salticidae and Thomisidae) based on the determination to the family level, following the "No web" classification of families/subfamilies in Cardoso et al. (2011; supplementary material table S1). The family Cheiracanthiidae, which was part of Miturgidae until recently (World Spider Catalog 2019) was classified by us as "free hunters" ("no web", like Miturgidae in Cardoso et al. 2011). For the classification into guilds, the Linyphiidae were determined to subfamily level (Erigoninae/Linyphiinae/Micronetinae; see Tanasevitch 2020). All material is deposited at the State Museum of Natural History Karlsruhe (SMNK).

\section{Statistical analysis}

All analyses were carried out in the R environment ( $R$ Core Team 2019). We applied separate models for each plant invader because both plant invaders are dominant in different habitat types in and around the city of Karlsruhe.

The total abundance of prey organisms, total spider abundance, abundance of guild types (web builders, free hunters) and the abundance of the two most dominant spider families (Philodromidae and Thomisidae) were correlated to plant stand type (factor: invaded vs. native) by using generalized linear mixed models (GLMM's) with a Poisson distribution for count data (R package 'Ime4'; Bates et al. 2019). (Paired) locations were used as random factor. The $p$ values are based on subsequent ANOVA (chisquare)testing (R package 'car'; Fox and Weisberg 2011). In the case of overdispersion, a negative binomial distribution was applied; in case of underdispersion, a Conway-Maxwell-Poisson (Lynch et al. 2014) distribution was used to fit the model (Magnusson et al. 2019). In cases of slight overdispersion in poisson models (sum of squared Pearson residuals/ residual degrees of freedom between 1.0 and 1.2) we used a function (Overdisp_fun) provided by Ben Bolker on the GLMM FAQ (Bolker 2020) for testing of overdispersion impact, but no significant impacts were found. This is also in accordance with Payne et al. (2018), who determined a general threshold of SSQP residuals/rdf of 1.2 under which a Poisson GLMM usually still performs well. We also tested for potential zero-inflation with 'testZeroInflation' in package DHARMa (Hartig 2020), which compares the number of zeros present in the dataset against the distribution of expected zeros in the model.

Spider family composition was related to plant stand type by using partial redundancy analysis (RDA) using the R package 'vegan' (Oksanen et al. 2017). To emphasize the influence of dominant families, a Hellinger transformation was performed. Because of our paired study design, we used partial RDA where we removed this effect (using the term Condition (pair) in the formula). The significance of the effect of plant stand type was tested using an ANOVA-like permutation test based on 999 permutations.

The map (Fig. 1) was created with package 'ggmap' (Kahle et al. 2019) and the 'terrain'-map of maps.stamen.com.

\section{Results}

Effect of American goldenrods and Himalayan balsam on potential spider prey items

American goldenrods had no significant effect on the number of potential spider prey item individuals (Table 1, Fig. 2a). In contrast, the presence of Himalayan balsam significantly affected the number of prey organisms (Table 1), which was on average almost two times higher in invaded than in native plots (Fig. 2b).

\section{American goldenrods}

We sampled 409 spider specimens from 12 spider families (supplementary material Table 2). We recorded 194 specimens from 10 families in plots invaded by American goldenrods and 215 specimens from 12 families in native plots. Only singletons represented exclusive families in native plots. The 
Table 1 Effect of Himalayan balsam (Impatiens glandulifera) and American goldenrods (Solidago canadensis/gigantea) on the individual number of prey items, total spider abundance,

\begin{tabular}{|c|c|c|c|c|c|c|}
\hline Dependent variable & Predictor & Estimate & SE & $\mathrm{z}$ & $\mathrm{p}$ & GLMM family \\
\hline \multirow[t]{2}{*}{ Prey items } & American goldenrod & -0.281 & 0.208 & -1.352 & 0.176 & n. binom \\
\hline & Himalayan balsam & 0.636 & 0.171 & 3.713 & $<0.001$ & n. binom \\
\hline \multirow[t]{2}{*}{ Spider abundance } & American goldenrod & -0.056 & 0.173 & -0.322 & 0.748 & n. binom \\
\hline & Himalayan balsam & -0.286 & 0.218 & -1.308 & 0.191 & n. binom \\
\hline \multirow[t]{2}{*}{ Thomisidae abundance } & American goldenrod & 0.350 & 0.139 & 2.523 & 0.012 & poisson \\
\hline & Himalayan balsam & -0.238 & 0.26 & -0.916 & 0.356 & compois \\
\hline \multirow[t]{2}{*}{ Philodromidae abundance } & American goldenrod & 0.032 & 0.252 & 0.126 & 0.900 & poisson \\
\hline & Himalayan balsam & -0.623 & 0.264 & -2.356 & 0.018 & poisson \\
\hline \multirow[t]{2}{*}{ Web builders } & American goldenrod & -0.962 & 0.151 & -6.384 & $<0.001$ & compois \\
\hline & Himalayan balsam & -0.289 & 0.300 & -0.964 & 0.335 & n. binom \\
\hline \multirow[t]{2}{*}{ Free hunters } & American goldenrod & 0.250 & 0.214 & 1.169 & 0.242 & n. binom \\
\hline & Himalayan balsam & -0.334 & 0.163 & -2.047 & 0.041 & poisson \\
\hline
\end{tabular}

Effects were tested with generalized linear mixed models (n.binom = negative binomial distribution) and subsequent ANOVA (chisquare)-testing. Significant effects are shown in bold abundance of the two most dominant spider families and of web builders and free hunters

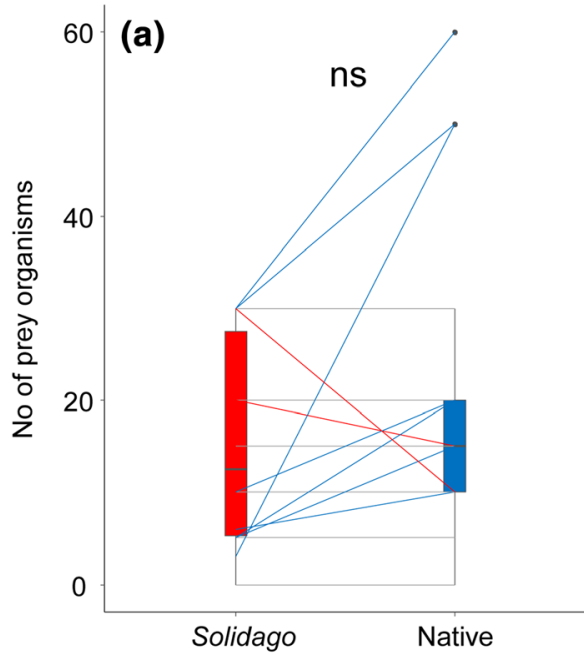

Fig. 2 Paired comparisons of the number of potential spider prey organism individuals between a American goldenrods ("Solidago") and native vegetation and b Himalayan balsam ("Impatiens") and native vegetation. Lines connect paired locations, whereby red lines indicate higher individual numbers

most abundant spider family were the crab spiders (Thomisidae; $\mathrm{n}=208$ ).

The total number of spider individuals showed no significant difference and little variation between American goldenrod and native plots (Table 1, Fig. 3a). On the family scale, the abundance of crab

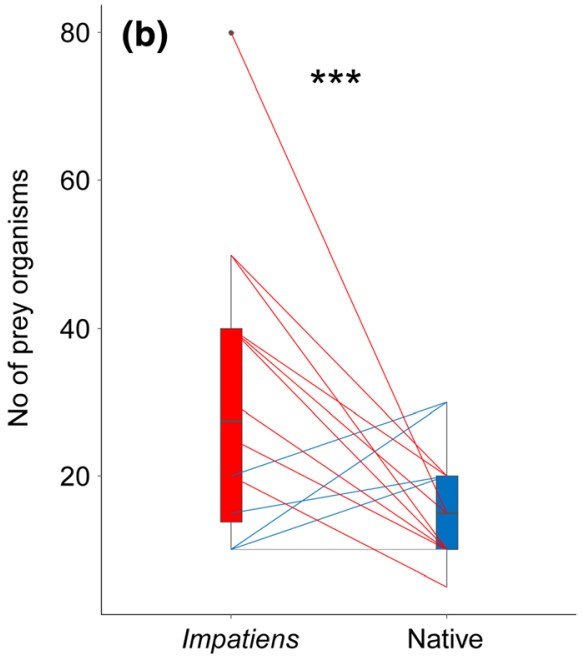

in the invaded plots, blue lines indicate higher individual numbers in the native plots and grey lines indicate similar individual numbers. Stars illustrate significant differences with $* * * p<0.001$ (ns not significant). For statistics see Table 1

spiders (Thomisidae) was significantly higher in plots invaded by American goldenrods than in native plots (Table 1, Fig. 3c). On the other hand, for the second most abundant spider family, the running crab spiders (Philodromidae), no significant effect on the abundance was found (Table 1, Fig. 3e). American 

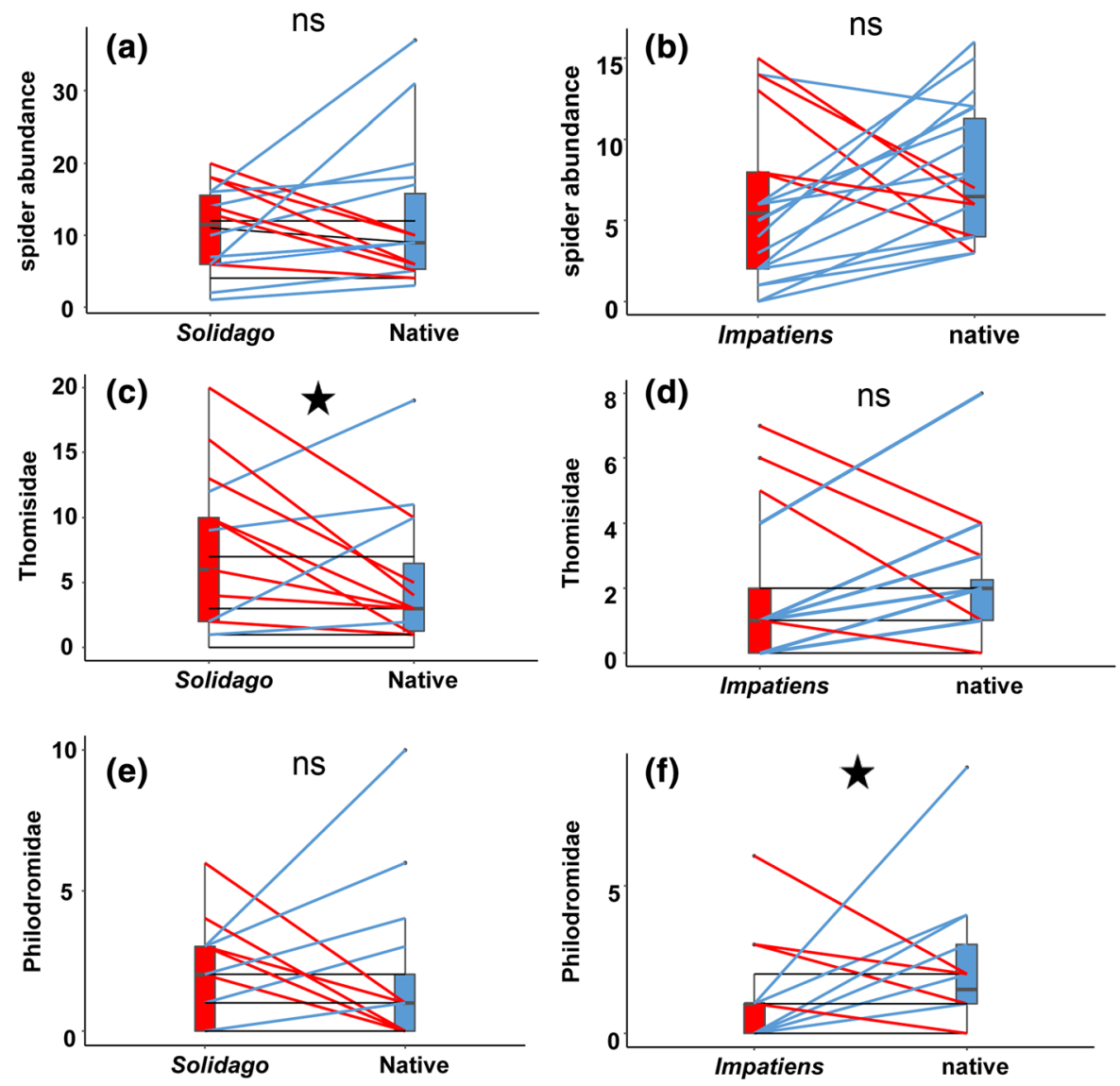

Fig. 3 Paired comparisons of abundances of total spiders $\mathbf{a}, \mathbf{b}$, Thomisidae c,d and Philodromidae e,f between American goldenrod (Solidago gigantea/canadensis) (left) and Himalayan balsam (Impatiens glandulifera) (right) with native vegetation. Lines connect paired locations, whereby red lines indicate

goldenrod had a significantly negative influence on the abundance of web builders, while, in contrast free hunters were not affected (Fig. 4a, b, Table 1).

Although we found more exclusive spider families occurring in native stands (see Venn diagrams in Fig. 5a), the family composition was highly similar between goldenrod and native vegetation stands. Compositions between both plant stand types showed large overlaps and did not differ significantly $(\mathrm{F}=1.076, \mathrm{P}=0.347$; Fig. 5a).

Himalayan balsam

We sampled 275 spider individuals from 12 families (supplementary material Table 2). 118 spider specimens were caught in plots invaded by Himalayan

higher individual numbers in the invaded plots, blue lines indicate higher individual numbers in the native plots and grey lines indicate equal individual numbers. Stars illustrate significant differences with $* p<0.05$ ( $n s$ not significant). For statistics see Table 1

balsam and 157 specimens in native plots. Invaded and native plots were inhabited by members of 11 spider families (10 shared), respectively. The most dominant spider families were the Thomisidae $(\mathrm{n}=72)$ and Philodromidae $(\mathrm{n}=63)$.

The total spider abundance was not significantly affected by plant stand type (Table 1, Fig. 3b). The two most dominant spider families showed different responses (Table 1, Fig. 3d, f). While abundances of Thomisidae showed high variability and were not significantly affected by plant stand type, Philodromidae abundances were significantly lower in invaded plots (Table 1). The abundance of free hunters was also significantly fewer in invaded plots, while web builders were not affected by the presence of Himalayan balsam (Fig. 4c, d, Table 1). 

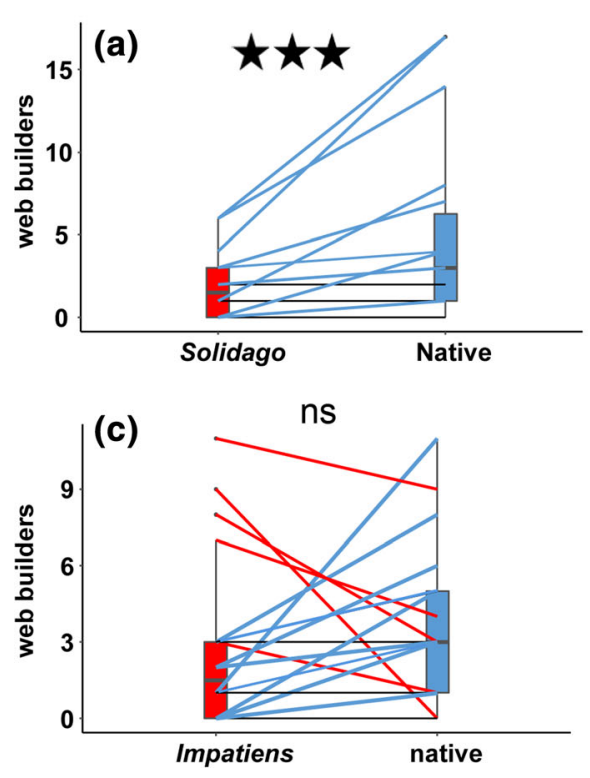

Fig. 4 Paired comparisons of the abundance of free hunters b,d and web builders a,c between American goldenrod (Solidago gigantealcanadensis) (top) and Himalayan balsam (Impatiens glandulifera) (bottom) with native vegetation. Lines connect paired locations, whereby red lines indicate higher

The spider family composition was not significantly affected by the plant stand type ( $\mathrm{F}=1.4$, $\mathrm{P}=0.2$; Fig. 5b). This is also reflected by the high number of families shared in both stand types (see Venn diagram in Fig. 5b).

\section{Discussion}

In general, flowering plant stands of alien American goldenrods and Himalayan balsam had only minor and statistically insignificant impacts on total spider abundances and family compositions. However, we could show that both plant invaders can affect abundances of the two dominant spider families as well as web builders and free hunters in contrasting ways. Even though we did not determine spiders to species level, all found effects affect mostly native spider species, since only very few alien spider species (and no alien thomisids or philodromids) occur in outdoor habitats in Germany (Blick et al. 2016, Nentwig et al. 2019).
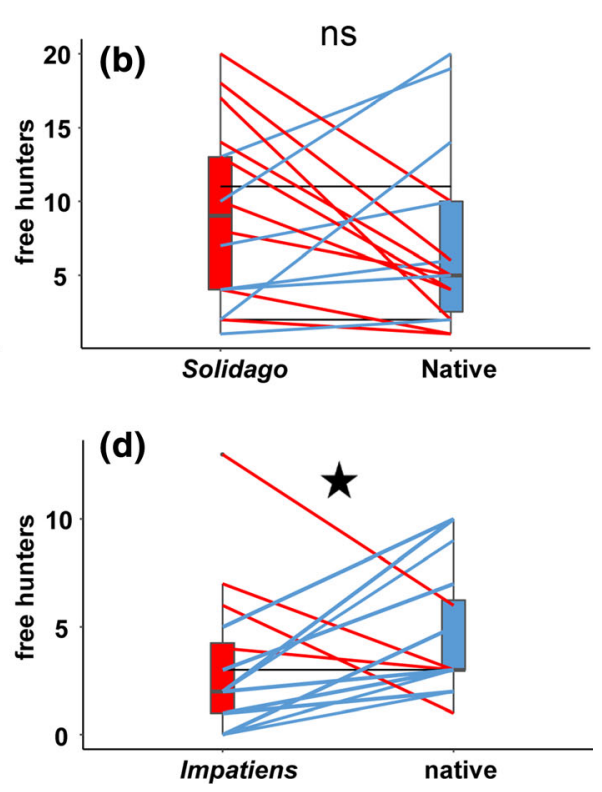

individual numbers in the invaded plots, blue lines indicate higher individual numbers in the native plots and grey lines indicate equal individual numbers. Stars illustrate significant differences with $* p<0.05$ and $* * * p<0.001$ ( $n s$ not significant). For statistics see Table 1

\section{American goldenrod}

In American goldenrod stands, significantly fewer web builders and more crab spiders were found than in native vegetation stands. This contrasts findings of Dudek et al. (2016), who showed that, in spring, dry stems of goldenrod stands are a preferred habitat of web-building araneids compared with native grass stands, probably due to the availability of more structures for orb-web building (Lubin 1978). The native plots in our study consisted of a dense mixture of grass and herbaceous plants, which may facilitate web building in contrast to the more homogeneous upper part of American goldenrod stands. The significant increased abundance of crab spiders on goldenrods might be explained by their preference for flowers as places to hide while preying on pollinating insects. Several crab spider genera from all continents are known to wait for prey directly on or beneath flowers, where they often catch pollinators larger than their own body size (Foelix 2011; Heiling et al. 2004; Huseynov 2007b; Morse 1983; Romero and Vasconcellos-Neto 2004a, b). Hence, the dense stands and the massive blooms of American goldenrod in late summer very likely attract crab spiders irrespectively 

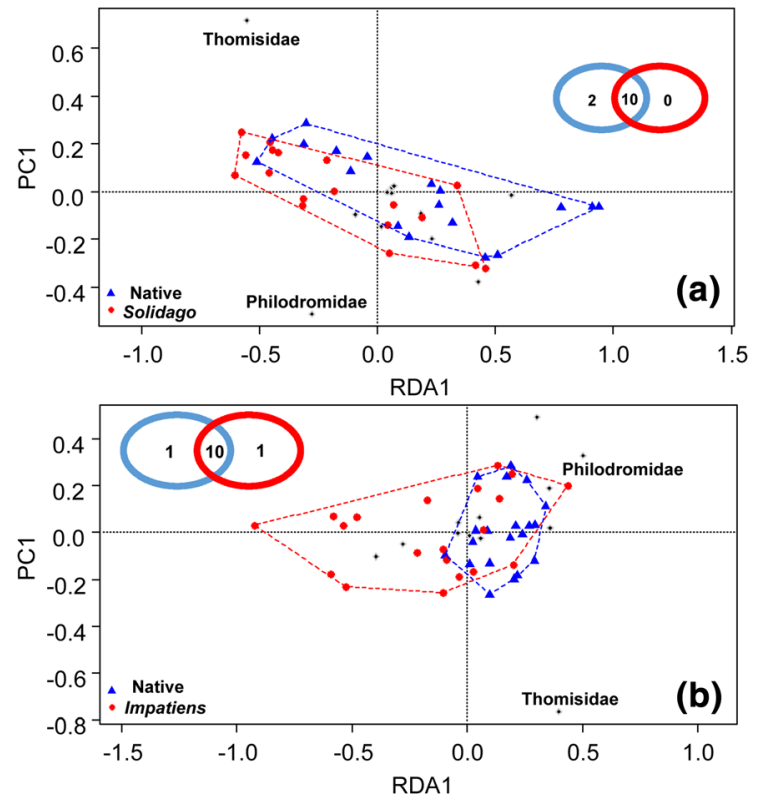

Fig. 5 RDA-ordination showing family composition in American goldenrod ("Solidago") and native vegetation stands a and in Himalayan balsam ("Impatiens") and native vegetation stands b. Inlets of Venn diagrams indicate the number of exclusive and shared spider families (red = plots invaded by Solidago/Impatiens, blue $=$ plots consisting of native vegetation). Dots represent the spider families (Thomisidae and Philodromidae are additionally labelled with text). For statistics see text

of the plants' non-native origin, but may also reduce the habitat of web-building spiders at the same time. The value of goldenrods for crab spiders is also reflected by Misumena vatia (Clerck, 1757), a species with a Holarctic distribution (World Spider Catalog 2019) which is sometimes called "goldenrod crab spider" in North America (Bradley 2013). North American specimens of this species are known for their preference of goldenrod flowers when given the choice between green parts and blooms of goldenrod plants in the laboratory (Morse 2000). However, many European crab spiders also prey on leaves and grassy vegetation (Gawryszewski et al. 2017), hence, the observed effect of American goldenrod on crab spiders might also be related to other, unknown factors.

Interestingly, there was no effect of goldenrod on potential prey items. It is known that alien goldenrod stands can be inhabited by a large number of polyphagous heteropterans, while specialized species are mostly absent (Roháčová and Drozd 2009). Although specialized herbivores might be missing, alien goldenrod still provides habitat for polyphagous insect species, which in turn serve as potential prey for spiders, as most species are opportunistic predators with a wide food niche (e.g., Foelix 2011; Huseynov 2007a, b, 2008; Nentwig 1986).

Himalayan balsam

In contrast to American goldenrods, flowering Himalayan balsam had no positive effects, but a negative effect on philodromid spiders as well as free hunters. In contrast to our hypothesis, no effects on crab spiders and web builders were found.

Himalayan balsam stands, when compared to native vegetation and American goldenrods (Weber 2000), promote erosion along riverbanks due to fast and synchronized diebacks after frost followed by a subsequent lack of vegetation cover and exposure of the underlying bare ground (Greenwood and Kuhn 2014). Bare ground is generally a less preferred overwintering habitat for spiders (Mestre et al. 2018) and possibly leads to a reduced abundance of certain spiders in dense stands of Himalayan balsam. In riparian habitats, this invader also negatively influences epigeic arthropod diversity and abundance in general, with heavily invaded regions differing from less-invaded sites (Seeney et al. 2019). Another reason for the reduced spider abundance, despite increased numbers of prey items, may be trophobiosis between ants and aphids on Himalayan balsam, which was incidentally observed in several plots during the study (FK and DAB pers. obs. during the field survey). Although some opportunistic spiders (including crab spiders) feed on ants (e.g., Huseynov 2007a, b), ants are known to be a difficult prey with some specialized spiders showing a very sophisticated predatory behavior (Heller 1976; Pekár 2004; Pekár et al. 2008). However, some spiders might avoid feeding on ants (e.g., the philodromid Tibellus macellus Simon, 1875; Huseynov 2008) and the abundance of web-building spiders can be reduced by these insects (Sanders and Platner 2007). Ants are known to protect aphids and act aggressively against potential aphid predators (Novgorodova and Gavryliuk 2012). A high ant density may therefore suppress the presence of some spiders which might especially be true for littlesclerotized species such as many members of Philodromidae, of which a significantly lower abundance was found on Himalayan balsam. Ant-spider 
interactions, including non-consumptive effects (Mestre et al. 2020), should therefore be targeted by future research.

That we found no differences in total spider abundance between Himalayan balsam and native reference vegetation might be related to the one-time sampling in late summer, in which a large number of juvenile spiders is present. Negative effects are potentially more pronounced when sampled over the complete vegetation period, as demonstrated for spiders in general by Tanner et al (2013). In addition, it has to be kept in mind that our results only present a "snapshot" of the system due to the limited sampling period. The damaging impact of the sweep net on flowering plants prevented a second as well as an earlier sampling (especially for the fragile Himalayan balsam stands).

\section{Conclusions}

In our studied urban environments, we found contrasting impacts of flowering American goldenrods and Himalayan balsam on plant-dwelling spiders. While both invasive plants had only minor impacts on total spider abundances and family compositions, they influenced the two most common families as well as the guild structure. Himalayan balsam negatively affected numbers of Philodromidae and free hunting spiders, with no positive effects on other groups. Removal of Himalayan balsam might therefore restore native spider communities (see also Tanner et al. 2013), but might also eliminate an important food resource for some pollinators in late summer (Davis et al. 2018).

Presence of American goldenrods had a positive influence on crab spider abundance, but a negative impact on web-builder abundance. Furthermore, total spider abundance was not negatively affected by this plant invader in our study. For American goldenrods, we therefore corroborate the hypothesis that some animal groups (in this case crab spiders) use nonnative plant species as a habitat analogue and might be facilitated by the presence of the alien plant to some extent (Davis et al. 2018; Rodriguez 2006; Russo et al. 2016). Based on our results, conservationists and administration should consider that a large-scale removal of invasive American goldenrod stands (Fenesi et al. 2015; Morón et al. 2009) during flowering season could negatively influence local spider abundances due to habitat loss. Additionally, mechanical mulching of goldenrod stands probably increases mortality of juvenile crab spiders dwelling on this plant invader. Compensation measures like sowing of native wildflower seeds with regional origin near the focal area or exclusion of ruderalized native vegetation from management activities like mowing might help to maintain local resources for those groups during and after the removal of this invasive plant invader.

It has to be kept in mind that our results are limited due to the single sampling event, and, more importantly, the impact of both invaders might strongly vary depending on the "novelty" of the ecosystem and the extent of habitat domination (see also Packer et al. 2016). For example, if American goldenrod species or Himalayan balsam invade protected conservation areas and replace diverse and structurally rich native plant communities, negative effects on insects and other arthropods can be assumed (Fenesi et al. 2015; Moroń et al. 2009).

In conclusion, we call for an integrated approach in the management of non-native plant invaders that keeps in mind the potential of plant invaders to facilitate some native arthropod groups, especially in urban and other novel habitats.

Acknowledgements We are very grateful to all reviewers for their constructive comments on previous versions of the manuscript. We are especially indebted to the editor Angela Chuang for providing numerous corrections and valuable suggestions that significantly improved the paper. Sebastian Kolb kindly helped with literature and statistics. Hubert Höfer and Sebastian Schmidtlein provided valuable comments on the dataset and analysis. We also thank Teagan Wernicke for her comprehensive linguistic help and the staff of the Gartenbauamt Karlsruhe for information on management of urban green spaces. Tobias Bauer was supported by a $\mathrm{PhD}$ scholarship of Friedrich-Ebert-Stiftung e.V.

Author contributions All authors contributed to the study conception and design. Material preparation, field work and data preparation were performed by Daria A. Bäte, Fabian Kempfer and Tobias Bauer. Analysis of data was performed by Tobias Bauer and Jens Schirmel. The manuscript was written by Tobias Bauer and all authors commented on previous versions of the manuscript. All authors read and approved the final manuscript.

Funding Open Access funding enabled and organized by Projekt DEAL. Tobias Bauer was supported by a PhDscholarship of Friedrich-Ebert-Siftung e.V. 
Availability of data and material Data are deposited in the Dryad data repository and will become available after publication under https://doi.org/10.5061/dryad.tdz08kpz5.

Code availability Standard R-codes from open accesssources described in the "Material and Methods" section were used.

\section{Compliance with ethical standards}

Conflict of interest The authors have no conflicts of interest to declare that are relevant to the content of this article.

Ethical approval Non-applicable.

Consent to participate Non-applicable.

Consent for publication All authors have consented to publish the revised version of the manuscript as it was submitted.

Open Access This article is licensed under a Creative Commons Attribution 4.0 International License, which permits use, sharing, adaptation, distribution and reproduction in any medium or format, as long as you give appropriate credit to the original author(s) and the source, provide a link to the Creative Commons licence, and indicate if changes were made. The images or other third party material in this article are included in the article's Creative Commons licence, unless indicated otherwise in a credit line to the material. If material is not included in the article's Creative Commons licence and your intended use is not permitted by statutory regulation or exceeds the permitted use, you will need to obtain permission directly from the copyright holder. To view a copy of this licence, visit http://creativecommons.org/licenses/by/4.0/.

\section{References}

Balkenhol B, Gebauer P, Lehmitz R (2018) Steeplebushes conquer the countryside: influence of invasive plant species on spider communities (Araneae) in former wet meadows. Biodivers Conserv 27:2257-2274. https://doi. org/10.1007/s10531-018-1536-8

Bates D, Maechler M, Bolker B et al. (2019) Package'lme4'. Version 1.1-21

Beerling DJ, Perrins JM (1993) Impatiens Glandulifera Royle (Impatiens Roylei Walp.). J Ecol 81:367-382

Bellard C, Cassey P, Blackburn TM (2016) Alien species as a driver of recent extinctions. Biol Lett 12:20150623. https:// doi.org/10.1098/rsbl.2015.0623

Blick T, Finch O-D, Harms KH, Kiechle J, Kielhorn et al (2016) Rote Liste und Gesamtartenliste der Spinnen (Arachnida: Araneae)Deutschlands. 3. Fassung, Stand April 2008, einzelne Änderungen und Nachträge bis August 2015. Naturschutz und Biologische Vielfalt 70(4):383-510

Boal CW, Dykstra CR (2018) Urban raptors: ecology and conservation of birds of prey in cities. Island Press, Washington, D.C.
Bolker B (2020): Function overdisp_fun. https://bbolker.github. io/mixedmodels-misc/glmmFAQ.html

Bradley R (1993) The influence of prey availability and habitat on activity patterns and abundance of Argiope keyserlingi (Araneae: Araneidae). J Arachnol 21:91-106

Bradley RA (2013) Common spiders of North America. University of California Press, Berkeley

Buchholz S (2010) Ground spider assemblages as indicators for habitat structure in inland sand ecosystems. Biodivers Conserv 19:2565-2595

Buchholz S, Tietze H, Kowarik I, Schirmel J (2015) Effects of a major tree invader on urban woodland arthropods. PLoS ONE 10(9):e0137723. https://doi.org/10.1371/journal. pone. 0137723

Buchholz S, Hannig K, Möller M, Schirmel J (2018) Reducing management intensity and isolation as promising tools to enhance ground-dwelling arthropod diversity in urban grasslands. Urban Ecosyst 21:1139-1149. https://doi.org/ 10.1007/s11252-018-0786-2

Cardoso P, Pekár S, Jocqué R, Coddington JA (2011) Global patterns of guild composition and functional diversity of spiders. PLoS ONE 6(6):e21710

Clausen IHS (1986) The use of spiders as ecological indicators. Bull Br Arachnol Soc 7(3):83-86

Čuda J, Vítková M, Albrechtová M et al (2017) Invasive herb Impatiens glandulifera has minimal impact on multiple components of temperate forest ecosystem function. Biol Invasions 19:3051-3066. https://doi.org/10.1007/s10530017-1508-z

Davis ES, Kelly R, Maggs CA, Stout JC (2018) Contrasting impacts of highly invasive plant species on flower-visiting insect communities. Biodivers Conserv 27:2069-2085. https://doi.org/10.1007/s10531-018-1525-y

Dostál P, Müllerová J, Pyšek P et al (2013) The impact of an invasive plant changes over time. Ecol Lett 16:1277-1284. https://doi.org/10.1111/ele.12166

Dudek K, Michlewicz M, Dudek M, Tryjanowski P (2016) Invasive Canadian goldenrod (Solidago canadensis L.) as a preferred foraging habitat for spiders. Arthropod Plant Interact 10:377-381. https://doi.org/10.1007/s11829-0169455-7

Eckert S, Möller M, Buchholz S (2017) Grasshopper diversity of urban wastelands is primarily boosted by habitat factors. Insect Conserv Diver 10(3):248-257

Entling W, Schmidt MH, Bacher S et al (2007) Niche properties of Central European spiders: shading, moisture and the evolution of the habitat niche. Glob Ecol Biogeogr 16:440-448

European Union (2014) Regulation (EU) No 1143/2014 of the European Parliament and of the Council of 22 October 2014 on the prevention and management of the introduction and spread of invasive alien species. https://eur-lex. europa.eu/legal-content/EN/TXT/?uri=celex\% 3A32014R1143

Fenesi A, Vágási CI, Beldean M et al (2015) Solidago canadensis impacts on native plant and pollinator communities in different-aged old fields. Basic Appl Ecol 16:335-346. https://doi.org/10.1016/j.baae.2015.03.003

Foelix RF (2011) Biology of spiders. Oxford University Press, New York 
Fox J, Weisberg S (2011) An R companion to applied regression, 2nd edn. Sage, Thousand Oaks CA

Gawryszewski FM, Calero-Torralbo MA, Gillespie RG et al (2017) Correlated evolution between coloration and ambush site in predators with visual prey lures. Evolution 71(8):2010-2021

Gerber E, Krebs C, Murrell C, Moretti M, Rocklin R, Schaffner U (2008) Exotic invasive knotweeds (Fallopia spp.) negatively affect native plant and invertebrate assemblages in European riparian habitats. Biol Conserv 141(3):646-654

Greenwood P, Kuhn NJ (2014) Does the invasive plant, Impatiens glandulifera, promote soil erosion along the riparian zone? An investigation on a small watercourse in northwest Switzerland. J Soils Sediments 14:637-650. https://doi. org/10.1007/s11368-013-0825-9

Hänggi A, Stöckli E, Nentwig W (1995) Lebensräume Mitteleuropäischer Spinnen. Charakterisierung der Lebensräume der häufigsten Spinnenarten Mitteleuropas und der mit diesen vergesellschafteten Arten. Centre suisse de cartographie de la fauna (CSCF).

Harry I, Höfer H, Schielzeth H, Assmann T (2019) Protected habitats of natura 2000 do not coincide with important diversity hotspots of arthropods in mountain grasslands. Insect Conserv Divers 12:329-338

Hartig F (2020) DHARMa: Residual Diagnostics for Hierarchical (Multi-Level / Mixed) Regression Models. R package version 0.3.0. http://florianhartig.github.io/DHARMa

Hausmann SL, Petermann JS, Rolff J (2016) Wild bees as pollinators of city trees. Insect Conserv Divers 9:97-107

Heiling AM, Cheng K, Herberstein ME (2004) Exploitation of floral signals by crab spiders (Thomisus spectabilis, Thomisidae). Behav Ecol 15:321-326

Hejda M, Pyšek P (2006) What is the impact of Impatiens glandulifera on species diversity of invaded riparian vegetation? Biol Conserv 132:143-152. https://doi.org/10. 1016/j.biocon.2006.03.025

Hejda M, Pyšek P, Jarošík V (2009) Impact of invasive plants on the species richness, diversity and composition of invaded communities. J Ecol 97(3):393-403

Heller G (1976) Zum Beutefangverhalten der ameisenfressenden Spinne Callilepis nocturna (Arachnida: Araneae: Drassodidae). Entomol Ger 3:100-103

Hoffmann BD, Broadhurst LM (2016) The economic cost of managing invasive species in Australia. NeoBiota 31:1-18. https://doi.org/10.3897/neobiota.31.6960

Hulme PE, Bremner ET (2006) Assessing the impact of Impatiens glandulifera on riparian habitats: partitioning diversity components following species removal. J Appl Ecol 43:43-50. https://doi.org/10.1111/j.1365-2664.2005. 01102.x

Hulme PE, Pyšek P, Jarošík V et al (2013) Bias and error in understanding plant invasion impacts. Trends Ecol Evol 28:212-218. https://doi.org/10.1016/j.tree.2012.10.010

Huseynov EF (2007a) Natural prey of the lynx spider Oxyopes lineatus (Araneae: Oxyopidae). Entomol Fenn 18:144-148

Huseynov EF (2007b) Natural prey of the crab spider Thomisus onustus (Araneae: Thomisidae), an extremely powerful predator of insects. J Nat Hist 41:2341-2349

Huseynov EF (2008) Natural prey of the spider Tibellus macellus (Araneae Philodromidae). Arachnology 14(4):206-208. https://doi.org/10.13156/100.014.0403
Kahle D, Wickham H, Kahle MD (2019). Package 'ggmap'. https://cran.r-project.org/web/packages/ggmap/ggmap.pdf

Karlsruhe R (1999) Landschaften und Böden im Regierungsbezirk Karlsruhe. E. Schweizerbart'sche Verlagsbuchhandlung, Stuttgart

Kowarik I (1995) On the role of alien species in urban flora and vegetation. In: Pyšek P, Prach K, Rejmánek M, Wade M (eds) Plant invasions: general aspects and special problems. SPB Academic Publishing, Amsterdam, pp 85-103

Lopezaraiza-Mikel ME, Hayes RB, Whalley MR, Memmott J (2007) The impact of an alien plant on a native plantpollinator network: an experimental approach. Ecol Lett 10:539-550. https://doi.org/10.1111/j.1461-0248.2007. 01055.x

Lubin YD (1978) Seasonal abundance and diversity of webbuilding spiders in relation to habitat structure on Barro Colorado Island, Panama. J Arachnol 6:31-51

Lynch HJ, Thorson JT, Shelton AO (2014) Dealing with underand over-dispersed count data in life history, spatial, and community ecology. Ecology 95:3173-3180. https://doi. org/10.1890/13-1912.1

Maerz JC, Blossey B, Nuzzo V (2005) Green frogs show reduced foraging success in habitats invaded by Japanese knotweed. Biodiv Conserv 14(12):2901-3291

Magnusson A, Skaug H, Nielsen A et al (2019) Package 'glmmTMB'. R Package Version 0.2.3

Mestre L, Schirmel J, Hetz J et al (2018) Both woody and herbaceous semi-natural habitats are essential for spider overwintering in European farmland. Agric Ecosyst Environ 267:141-146. https://doi.org/10.1016/j.agee. 2018.08.018

Mestre L, Narimanov N, Menzel F, Entling MH (2020) Nonconsumptive effects between predators depend on the foraging mode of intraguild prey. J Anim Ecol. https://doi. org/10.1111/1365-2656.13224

Moroń D, Lenda M, Skórka P et al (2009) Wild pollinator communities are negatively affected by invasion of alien goldenrods in grassland landscapes. Biol Conserv 142:1322-1332. https://doi.org/10.1016/j.biocon.2008.12. 036

Morse DH (1983) Foraging patterns and time budgets of the crab spiders Xysticus emertoni Keyserling and Misumena vatia (Clerck) (Araneae: Thomisidae ) on flowers. J Arachnol 11:87-94

Morse DH (2000) Flower choice by naive young crab spiders and the effect of subsequent experience. Anim Behav 59:943-951

Nehring S, Kowarik I, Rabitsch W, Essl F (2013) Naturschutzfachliche Invasivitätsbewertungen für in Deutschland wild lebende gebietsfremde Gefäßpflanzen. BfN-Skripten 352:1-202

Nentwig W (1986) Non-webbuilding spiders: prey specialists or generalists? Oecologia 69(4):571-576

Nentwig W, Bacher S, Kumschick S et al (2018) More than "100 worst" alien species in Europe. Biol Invasions 20:1611-1621. https://doi.org/10.1007/s10530-017-16516

Nentwig W, Blick T, Bosmans R, Gloor D, Hänggi A, Kropf C (2019) Spinnen Europas. Version 10.2019. Online https:// www.araneae.nmbe.ch 
Novgorodova TA, Gavrilyuk AV (2012) The degree of protection different ants (Hymenoptera: Formicidae) provide aphids (Hemiptera: Aphididae) against aphidophages. Eur J Entomol 109:187-196. https://doi.org/10.14411/eje. 2012.025

Oksanen AJ, Blanchet FG, Friendly M, et al (2017) Package 'vegan'. https://cran.r-project.org/web/packages/vegan/ vegan.pdf

Packer JG, Delean S, Kueffer C et al (2016) Native faunal communities depend on habitat from non-native plants in novel but not in natural ecosystems. Biodivers Conserv 25:503-523. https://doi.org/10.1007/s10531-016-1059-0

Payne EH, Gebregziabher M, Hardin JW et al (2018) An empirical approach to determine a threshold for assessing overdispersion in poisson and negative binomial models for count data. Commun Stat Simul Comput 47:1722-1738. https://doi.org/10.1080/03610918.2017. 1323223

Pearson DE (2009) Invasive plant architecture alters trophic interactions by changing predator abundance and behavior. Oecologia 159:549-558. https://doi.org/10.1007/s00442008-1241-5

Pekár S (2004) Predatory behavior of two European ant-eating spiders (Araneae, Zodariidae). J Arachnol 32:31-41. https://doi.org/10.1636/s02-15

Pekár S, Toft S, Hrušková M, Mayntz D (2008) Dietary and prey-capture adaptations by which Zodarion germanicum, an ant-eating spider (Araneae: Zodariidae), specialises on the Formicinae. Naturwissenschaften 95:233-239. https:// doi.org/10.1007/s00114-007-0322-3

Pimentel D, Zuniga R, Morrison D (2005) Update on the environmental and economic costs associated with alien-invasive species in the United States. Ecol Econ 52:273-288. https://doi.org/10.1016/j.ecolecon.2004.10.002

Procheş Ş, Wilson JRU, Richardson DM, Chown SL (2008) Herbivores, but not other insects, are scarce on alien plants. Austral Ecol 33:691-700. https://doi.org/10.1111/j.14429993.2008.01836.x

R Core Team (2019) R: A language and environment for statistical computing. R Foundation for Statistical Computing, Vienna. http://www.R-project.org/

Rodriguez LF (2006) Can invasive species facilitate native species? Evidence of how, when, and why these impacts occur. Biol Invasions 8:927-939. https://doi.org/10.1007/ s10530-005-5103-3

Roháčová M, Drozd P (2009) How many heteropteran species can live on alien goldenrods Solidago canadensis and $S$. gigantea in Europe? Biologia (Bratisl) 64:981-993. https:// doi.org/10.2478/s11756-009-0151-2

Romero GQ, Vasconcellos-Neto J (2004a) Foraging by the flower-dwelling spider, Misumenops argenteus (Thomisidae), at high prey density sites. J Nat Hist 38:1287-1296

Romero GQ, Vasconcellos-Neto J (2004b) Beneficial effects of flower-dwelling predators on their host plant. Ecology 85:446-457. https://doi.org/10.1890/02-0327
Russo L, Nichol C, Shea K (2016) Pollinator floral provisioning by a plant invader: quantifying beneficial effects of detrimental species. Divers Distrib 22:189-198. https://doi.org/ 10.1111/ddi.12397

Sala OE, Chapin FS, Armesto JJ et al (2000) Global biodiversity scenarios for the year 2100. Science 287:1770-1774. https://doi.org/10.1126/science.287.5459.1770

Sanders D, Platner C (2007) Intraguild interactions between spiders and ants and top-down control in a grassland food web. Oecologia 150:611-624. https://doi.org/10.1007/ s00442-006-0538-5

Schirmel J, Bundschuh M, Entling MH et al (2016) Impacts of invasive plants on resident animals across ecosystems, taxa, and feeding types: a global assessment. Glob Chang Biol 22:594-603. https://doi.org/10.1111/gcb.13093

Seeney A, Eastwood S, Pattison Z, Willby NJ, Bull CD (2019) All change at the water's edge: invasion by non-native riparian plants negatively impacts terrestrial invertebrates. Biol Invasions 21(6):1933-1946. https://doi.org/10.1007/ s10530-019-01947-5

Simberloff D, Martin JL, Genovesi P et al (2013) Impacts of biological invasions: what's what and the way forward. Trends Ecol Evol 28:58-66. https://doi.org/10.1016/j.tree. 2012.07.013

Tanasevitch AV (2020) Linyphid spiders of the World. http:// old.cepl.rssi.ru/bio/tan/linyphiidae. Accessed 10 June 2020

Tanner RA, Varia S, Eschen R, Wood S et al (2013) Impacts of an invasive non-native annual weed, Impatiens glandulifera, on above-and below-ground invertebrate communities in the United Kingdom. PLoS ONE 8(6):e67271. https:// doi.org/10.1371/journal.pone.0067271

Weber E (2000) Biological flora of Central Europe: Solidago altissima L. Flora 195:123-134. https://doi.org/10.1016/ S0367-2530(17)30960-X

Westrich P (2019) Die Wildbienen Deutschlands, 2nd edn. Eugen Ulmer Verlag, Stuttgart

White EM, Wilson JC, Clarke AR (2006) Biotic indirect effects: a neglected concept in invasion biology. Divers Distrib 12:443-455. https://doi.org/10.1111/j.1366-9516.2006. 00265.x

Wise DH (1979) Effects of an experimental increase in prey abundance upon the reproductive rates of two orb-weaving pider species (Araneae: Araneidae). Oecologia 41:289-300

World Spider Catalog (2019) World Spider Catalog. Version 20.5. Natural History Museum Bern. http://wsc.nmbe.ch, accessed on 10 October 2019

Publisher's Note Springer Nature remains neutral with regard to jurisdictional claims in published maps and institutional affiliations. 